\title{
Sin programa. Aprendizaje proyectual en arquitectura a través de la enunciación
}

\section{Resumen}

Esta investigación tiene como objetivo principal descentrar la enseñanza del proyecto arquitectónico a través del programa para proponerla desde la enunciación. Como método, crea un dispositivo discursivo elaborado sobre la comprensión de que quien proyecta es un ser contemporáneo, que habita en una realidad que está construida a partir de discursos. Es entonces que este dispositivo se estructura en ocho estadios que trabajan el proceso de proyección arquitectónica desde una perspectiva discursiva y experiencial. Como resultado, se explican cuatro de las enunciaciones desarrolladas para este artículo como una demostración de las experiencias de este proceso. Estas enunciaciones versan sobre distintos temas de la arquitectura: "El origen es ahora principio de impermanencia", donde el origen es el lugar fundacional de la ciudad de Maracaibo, la costa; el principio indica otro modo de inserción arquitectónica. "Naturalezas compatibles" como el modo de sensibilizar hacia relaciones armónicas entre la arquitectura y el ecosistema en el que se inserta. "Sobre las sobras", propone repensar desde la arquitectura, los paisajes residuales. "La casa de Alicia en el país de las maravillas" se piensa como el medio para la vida de una familia disfuncional, a partir de la cual se proyecta una CASA no del autor sino del morador. Se concluye, entonces, que este modo de enseñanza del proyecto arquitectónico fortalece las capacidades propositivas y heurísticas de quien aprende; sitúa en quien aprende en su contemporaneidad y desde allí lo transforma para conciliar el lugar con la vida humana; explora en la práctica reflexiva como generación de conocimiento en un contexto Latinoamericano; y saca el aprendizaje de lo programático para convertirlo en experiencia heurística que surge desde lo discursivo como naturaleza de la realidad.

\author{
María Verónica \\ Machado Penso \\ Doctora en Arquitectura \\ Universidad de la Costa \\ Barranquilla - Colombia \\ Correo electrónico: \\ mmachado@cuc.edu.co, \\ mmpenso@hotmail.com \\ ๑ orcid.org/0000-0001-8727-3666 \\ Google Scholar
}

Recibido: abril 11 de 2019 Aprobado: octubre 29 de 2020

Key words:

estrategias pedagógicas, proyecto arquitectónico, discurso contemporáneo. 


\section{No Program. Design learning in architecture through enunciation}

\begin{abstract}
The main objective of this research is to decentralize the teaching of the architectural project following an academic program to propose it from the enunciation. As a method, it creates a discursive device elaborated on the understanding that the designer is a contemporary being who lives in a reality that is constructed from discourses. It is then that this device is structured in eight states that work on the architectural process from a discursive and experiential perspective. As a result, four of those states are developed and explained in this article, as a demonstration of the experiences of this process. These statements deal with different themes of architecture: "The origin is now the principle of impermanence", where the origin is the founding place of the city of Maracaibo, the coast. The principle indicates the criterion of another form of architectural insertion. "Compatible natures" as the way of raising awareness towards harmonious relationships between architecture and the ecosystem in which it is inserted. "On the leftovers", proposes to rethink residual landscapes from architecture. "Alice's house in wonderland" is thought of as the means for the life of a dysfunctional family, from which a HOUSE is projected not of the author but of the inhabitant. It is concluded then, that this way of teaching the architectural project strengthens the purposeful and heuristic capacities of the learner, placing him in his contemporaneity and transforming him to reconcile the place with human life. It explores the reflective practice as a source of knowledge in the Latin American context and it pulls out learning from the programmatical system to turn it into a heuristic experience that arises from the discursive as the nature of reality.
\end{abstract}

Key words: pedagogic strategies, architectural project, contemporary discourse. 


\section{Introducción}

El proyecto procede etimológicamente como sustantivo del verbo proyectar, como ese arrojar, echar adelante (Corominas, 1985). Implica que, desde el presente, traza y pone en la realidad lo que se ha pensado desde su locus de enunciación. Un lugar que en la modernidad estaba puesto en la razón universal como rectora del conocimiento y que en esta contemporaneidad se ha atomizado y se ha puesto en particularidades individuales que involucran expresión y experiencia. Si circunscribimos el proyectar arquitectónico a esta contemporaneidad, este viene dado desde una particularidad que actúa en diferencia y no como en la modernidad, que actuaba desde concepciones universales. Es esta individualidad la que impulsa los testimonios del presente y el pasado, para arrojar al presente una idea de futuro. Es entonces que quien proyecta le corresponde ser en conciencia contemporáneo.

No basta ser contemporáneo cuando se tiene conciencia de que "siendo se es" (Cordero, 2005) sensible a acciones sustanciales y circunstanciales. Se es contemporáneo, según Giorgio Agamben, cuando se está triplemente implicado: primero, no coincidir a la perfección con el tiempo presente. Segundo, "mantiene la mirada fija en su tiempo, para percibir, no sus luces, sino su oscuridad" (Agamben, 2011a, p. 21), es decir, conoce concienzudamente las características de su tiempo y ve más allá de sus apariencias. Tercero, es

quien, dividiendo e interpolando el tiempo, está en condiciones de transformarlo y ponerlo en relación con los otros tiempos, de leer en él de manera inédita la historia, de "citarla" según una necesidad que no proviene en modo alguno de su árbitro sino de una exigencia a la que él no puede dejar de responder. (Agamben, 2011a, pp. 28-29)

Es decir, atraviesa el tiempo y desde las relaciones que entabla, responde a lo velado del presente. Estas tres instancias de ser contemporáneo son inherentes a quien tiene la tarea de proyectar arquitectura, a quien proyecta espacios para 
la cotidianidad y lo intempestivo, ya que esta es una labor (Arendt, 2009) que, en la contemporaneidad, no impone modelos, sino que comprende la realidad en su tiempo y fuera de sus tiempos y desde allí formula modos de habitar como una relación en conciliación.

Es así como a quien piensa y produce la arquitectura, le corresponde estar entrenado para saber, ver, leer, escuchar y reconocer, en lo dado, lo que esto esconde y lo que todavía no es. Desde allí, pensar y actuar en consecuencia. Esto es: extraer el subtexto de la realidad y con ello pro-poner. Interpretar para poner y arrojar en la realidad lo que desde ella se ha pensado como proyecto. Proyecto que le corresponde iniciar en la interpretación de los modos de ser en el mundo, cuyo proceso se aborda desde el discurso, ya que la realidad humana según determina Pinardi: "(...) está hecha de significación y que la significación se estructura en sistemas discursivos (...)" (2015, p. 3). Este pronunciamiento hace patente la inherencia del discurso y la práctica en la constitución de la realidad humana. Son dos conceptos (discurso y praxis) los que se han tomado para la formulación de un dispositivo que "disponga" de los procesos de proyectación arquitectónica, surgidos desde la enunciación y conducidos por una práctica experiencial y heurística de la enseñanza del proceso arquitectónico.

Anatxu Zabalbeascoa (2012) en su artículo "Muerte no, dimisión sí", enuncia:

La arquitectura contemporánea está Ilena de lecturas, ideas y propuestas que consiguen explicar el paisaje y los lugares a quien aprende a leerlas $-\mathrm{y}$, con ganas de mirar, se puede aprender un poco más de una visita- (...) La mejor arquitectura explica, conmueve y ayuda. Enseña a mirar. Eso si, para mirar es necesario querer ver. (Zabalbeascoa, 2012)

La idea expuesta por Zabalbeascoa es cónsona con la idea de realidad contemporánea entendida como significación, expuesta por Pinardi (2015), transcrita ahora en el campo de la arquitectura. Consonancia que afianza 
el concebir y enseñar a proyectar la arquitectura mediante un dispositivo que surja desde el discurso, que se construya a partir de él y cuyo resultado también manifieste un discurso que evidencie la contemporaneidad. Discursos arquitectónicos alejados de la epistemología del programa en los talleres de arquitectura e inmersos en la interpretación de "experiencias, acontecimientos, significaciones o interpretaciones" (Pinardi, 2015, p. 3). Discursos manejados, fundamentalmente, por la experiencia de ese ser contemporáneo en un mundo siempre en construcción. La experiencia entendida aquí "como énfasis de lo vivido, en la percepción de los sentidos y en la experimentación" (Montaner, 2014, p. 77), es decir antepuesta a la idea de programa. Y es de esta anteposición que pueden derivarse tres polaridades: 1) Mientras lo programático está dispuesto, la experiencia implica una desprogramación y una comprensión de las posibilidades del ser humano en el espacio, entregándose así a la incertidumbre espacial. 2) Lo que la zonificación separa en el programa, la experiencia la convierte en relación, fusión, superposición, cruce, etc. 3) Si el programa especializa, la experiencia mezcla. Son estos sentidos de la experiencia que, ante lo programático, se abordan ahora desde una comprensión discursiva del mundo contemporáneo.

Es así como la arquitectura, circunscrita en una proyectación desde lo discursivo, prescrita desde la enunciación, inscrita en una "textura del mundo lingüística y semántica" (Pinardi, 2015, p. 3), escrita desde un ser conciente de su contemporaneidad y de su lugar en ella, descrita por significaciones propias que parten de la realidad, reescrita mediante experiencias de quienes la habitan y adscrita a la contemporaneidad, le corresponde anunciar apertura (Gausa, 2005; Brisotto et al., 2019), enunciar relaciones (Montaner, 2008; Allen, 1997), renunciar a la razón reguladora (Holl, 2011; Soriano, 2004; Fujimoto, 2010), denunciar imposición (Juaçaba, 2015) y pronunciar posibilidad (Juarranz Serrano, 2017). 
La arquitectura contemporánea está hecha de relaciones entre las cosas, hechos, acontecimientos, situaciones, significaciones e interpretaciones (Pinardi, 2015), que resaltan ante la primacía del objeto. Es la noción de campo (Allen, 1997) la que predomina. Incluso, esta visión de la arquitectura desde el campo podría diferenciarse notablemente de la visión de la arquitectura enunciada como paisaje (Gausa, 2001; Abalos, 2005; Montaner, 2008; García-Hípola, 2014) que, si bien busca entender el paisaje como el todo y desde allí gestar la arquitectura en relación intrínseca con él, en la noción de campo domina el "entre" las cosas, que se encuentran en el paisaje. Es decir, no se trata de insertar o mimetizar cosas en el paisaje, sino entender su tránsito entre ellas.

Estas condiciones de ser contemporáneo, la realidad discursiva y los modos de la arquitectura contemporánea, dan pie a transformar el proceso de diseño que en un tiempo epistemológico dependió de la función a partir de la noción de programa. Ahora, inscritos en una realidad estructurada en sistemas discursivos, se atisba hacerlo desde la enunciación, ya que al circunscribirse en esa realidad contemporánea y "gracias a la idea de enunciación podemos pensar los actos humanos como inscripciones significativas o significantes en las que el mundo y los discursos se ven afectados" (Pinardi, 2015, p. 4). Es así como la enunciación en el proyecto de diseño toma el mando desde un dispositivo discursivo que se dispone en ocho estadios. El objetivo de este artículo es explicar cómo el dispositivo discursivo, que parte de la enunciación, se ha constituido como un modo de enseñanza del proyecto arquitectónico en la Facultad de Arquitectura de la Universidad del Zulia.

\section{Método. El dispositivo discursivo para el aprendizaje del proyecto arquitectónico desde la enunciación}

Los enunciados desde los cuales se proponen y se inicia el proceso de enseñanza de la proyectación arquitectónica, surgen de reflexiones que abordan asuntos 
contemporáneos que competen directamente al lugar desde donde se proyecta la arquitectura contemporánea. Cada uno se materializa como una sentencia enigmática, que vela el sentido de donde procede. La intención es interpelar al participante, para que este responda desde el lugar del conocimiento donde se encuentra en cualquier paso del proceso. Es así como se plantea un dispositivo (Deleuze, 2009; Foucault, 1977; Agamben, 2011b) discursivo (Pinardi, 2015; Austin, 1955; Ricoeur, 2001). Dispositivo porque, en principio, desde él se dispone el proceso de concepción y ejecución del proyecto arquitectónico. Este concepto fue utilizado por Foucault para desarrollar su filosofía; ha sido analizado por Giorgio Agamben (2011b) y Gilles Deleuze (2009), los cuales dan luz a la comprensión de la propuesta del dispositivo discursivo como medio para el aprendizaje del proyecto arquitectónico que parte de la enunciación.

Es mediante el dispositivo discursivo, a través de la enunciación, que el participante dilucida lo que implica la sentencia que guarda y cómo esta se transforma en concreción arquitectónica a través de un proceso de aprendizaje. Se conforma así un ambiente en disposición para la transformación del ser en un sujeto proyectante. La gestación y materializaron del proyecto de naturaleza discursiva está anclada en la palabra y el concepto de texto, desde el cual se deriva y despliega su acción. Es así que se apropia de los prefijos y sufijos de la palabra texto para reconfigurar su propia enunciación, de esta manera se obtiene: texto, subtexto, pre-texto, hiper-texto, con-texto, textura y contextura. Ocho expresiones ${ }^{1}$ que, desde su naturaleza como acciones procesuales, entran dentro de lo que Austin (1955) denomina enunciación performativa, cuyo acto locucionario ya implica una acción.

De esta manera, se convierte el sema de estas ocho enunciaciones en acción, cada uno define y actúa sobre las enunciaciones, así, hasta llegar al proyecto

${ }^{1}$ Algunos aspectos en el desarrollo de los conceptos: sub-texto e hiper-texto se realizan a partir de la ponencia presentada en I International Conference on Architectural Design \& Criticism, titulada:____TXT | TXT___ | TXT. Las derivaciones del texto enuncian las acciones arquitectónicas. 
de arquitectura iniciado en reflexiones y juicios emitidos a partir del enunciado propositivo. Cada uno de ellos es evidencia de la inherencia que tienen en el proceso: reflexión crítica, observación, investigación, experimentación y experiencia en la práctica de la proyectación arquitectónica. Se piensa la teoría desde la práctica y desde la teoría misma, se hace reflexión crítica desde testimonios y posturas, las observaciones conducen a inmersiones, se investiga a través de la experimentación y teorización, se experimenta a través de lecturas y experiencias y se experiencia desde la contemplación e inmersión. Este proceso conlleva a un acto, que es acta, ya que escribe las instancias que activa la inteligencia sentiente (Xubirí, 2004) a través de estas ocho expresiones que se explican a seguir.

El texto lo constituye el enunciado que inicia el proceso, es el acto que encubre una intención, es el encargado de interpelar a quien aprende, vela una proposición, invita a un discernimiento, convoca a pensar lo que implican las palabras y sus sentidos. El texto es una unidad formada por un conjunto de significados de sentido que poseen una intención y estructura configuradas de acuerdo con la intención de quien enuncia.

El texto, como enunciación e idea inicial, germina las posibilidades en la visión de la arquitectura y el aprendizaje de quien es participe, ya que en esta concreción se conjugan las potencialidades a explorar desde la singularidad que cada uno representa. Es en este estadio donde se incide en la comprensión, crítica, concienciación de la intuición y escritura del texto necesario para reseñar y entender más en profundidad la arquitectura.

El sub-texto es el sentido que cada estudiante percibe en el texto de enunciación. Es abordado luego del texto como enunciación y antes de la textura, materialización. En este, cada participante explica el contenido del concepto que le conferirá a su arquitectura. Es la expresión singular que 
aporta cada uno para construir un enunciado plural. Habla desde la poética, subjetividad, delirio, racionalidad, emoción, invención, teoría, lógica, sentido del humor, etc. Define un propósito sin parámetros determinados. Abre el campo a las posibilidades de opciones para llegar al proyecto. El sub-texto aquí propuesto, es postextual (Porras Collantes, 1981), ya que constituye la conclusión y el resultado de una operación inductiva en inventiva, en la que intervienen —como premisas - el enunciado, el sema y su deducción. El sub-texto se elabora a través de procedimientos mediadores y mediatizados, ya que media entre las premisas y el argumento para llegar a la conclusión que, en este caso, es el proyecto arquitectónico (Porras Collantes, 1981). El sub-texto, en su segunda fase, constituye el medio de desarrollo de la singularidad arquitectónica, el procedimiento desde el cual puede expresarse y evidenciarse la postura de quien crea. En este estadio del dispositivo, el participante integra los discernimientos elaborados en el texto, las conclusiones particulares y colectivas extraídas en el hiper-texto y las síntesis del con-texto, para interpretarlos desde un pensamiento crítico.

El híper-texto es un estadio que relaciona una selección de lecturas en torno a la enunciación y a la arquitectura contemporánea para hacer conexiones entre ellas y establecer relaciones de sentido que se han extraído de la enunciación. Surgen entonces, especulaciones en torno a la enunciación que configura los argumentos individuales para la gestación del proyecto. Se basa en el discernimiento, discusión y aprehensión de ideas, pensamientos, teorías y posiciones de autores de cualquier época y disciplina, pero, sobre todo, autores y actores contemporáneos que hayan investigado y producido en relación con la idea que se maneja en la enunciación. Rafael Moneo (2004) en su libro "Inquietud teórica y estrategia proyectual en la obra de ocho arquitectos contemporáneos", corrobora parcialmente esta idea cuando afirma: "siempre he creído que las escuelas de arquitectura deberían prestar atención a la escena contemporánea, a aquellos arquitectos que todavía no han pasado al olimpo 
de los manuales" (p. 5). Es así como el híper-texto se apoya parcialmente en la idea de Moneo, porque no solo se lee sobre aportes en la arquitectura, sino en disciplinas como filosofía, literatura, sociología, urbanismo y otras que aborden la enunciación planteada desde una perspectiva relacionada con lo que se persigue en la elaboración del proyecto.

La dinámica por seguir en el híper-texto se establece mediante varios mecanismos participativos: el primero define la lógica de interacción entre la serie de lecturas y el orden en el cual se realizarán. El segundo asigna a cada estudiante, de acuerdo con su experiencia e inclinación hacia la arquitectura, una lectura lo más afín posible con la idea de despertar su interés espontáneo. El tercero lo constituye la discusión y lectura colectiva de los textos. El cuarto consiste en la elaboración de una síntesis de las lecturas particulares nutridas por las ideas expuestas en las discusiones. Como quinto mecanismo, se abordan también testimonios de la arquitectura y otras artes en diferentes períodos de tiempo, desde la interpretación, suposición, especulación y cruce de experiencias. En esta etapa se ejercitan varios aspectos del aprendizaje: lectura, crítica, participación, iniciativa, escritura, concienciación de la intuición, especulación, interpretación, síntesis, abstracción; todas ellas alimentan el proceso creativo, estimulan la generación de ideas e incrementan el imaginario. Desde aquí se activan el pensamiento crítico y especulativo y la acción crítica encadenada a la idea de proposición proyectual.

Desde un con-texto comprendido a partir de cinco acepciones: 1) "enunciado o conjunto de enunciados coherentes", 2) el "entorno físico o de situación, ya sea político, histórico, cultural o de cualquier otra índole, en el cual se considera un hecho" 3) "enredo o unión" de circunstancias, dimensiones, acontecimientos, modos, maneras y formas que se "enlazan y entretejen" (Real Academia Española, s.f., definición 2), 4) el "conjunto de elementos que condicionan, de cualquier modo, el significado" (Martínez 
y Martínez 1997), 5) aquella circunstancia basada en el texto que modifica su apariencia, pero no su esencia.

En el con-texto se hace un abordaje experiencial y mapificado en el conocimiento del lugar. Se aborda la experiencia en el sitio, se realiza un proceso de inmersión en el lugar y sus alrededores, se extraen de manera individual y colectiva las sensaciones y características espaciales del lugar y, por último, se hace contacto con sus habitantes para conocer las condiciones sociales. Este conocimiento generado por el contacto espacial y social del lugar es sintetizado y diagramado para ser complementado con información morfológica, económica, política, cultural, y de cualquier otra índole que sea inherente al estudio del lugar, para configurar las actividades desde la particularidad del lugar.

En este paso del proceso se activan varios componentes propios para la creación y proyectación, como lo son: inmersión en el lugar, investigación, crítica, lectura de planos, síntesis, concienciación de la intuición, abstracción, iniciativa, expresión gráfica y redacción. De esta manera, nutre de ideas a cada uno de los participantes para la gestación conceptual del proyecto arquitectónico. Pero antes de gestar el proyecto, y como es necesario decantar las ideas mientras se procesan de manera inconsciente, se realiza una desviación en el camino, en la cual se dispone a realizar un breve ejercicio que puede ser experiencial, deductivo o experimental; este desvío es el pre-texto.

El pre-texto constituye un experimento de entrenamiento teórico o práctica para casos extremos. Busca preparar a los estudiantes en la aprehensión de los modos de abordar un acto creativo de manera inmediata e instantánea. El pre-texto es desde esa distracción de cambio abrupto que se lleva a cabo de manera distraída un asentamiento de los conocimientos adquiridos. El término pre-texto es entendido aquí como "motivo o causa simulada o aparente que se 
alega para hacer algo o para excusarse de no haberlo ejecutado" (Real Academia Española, s.f., definición 1). Constituye entonces el desvío y un salto en el proceso de proyectación arquitectónica para sumergirse en la teoría o práctica arquitectónica, mediante hechos efímeros de resolución instantánea de problemas espaciales. Son experimentos cortos, de un día o una semana de duración, que se presentan también para cuestionar los tiempos de la arquitectura y la posibilidad de formulación de opciones construidas de manera instantánea. En esta fase, se articulan una suma de propiedades inherentes a la proyectación arquitectónica: comprensión, crítica, investigación, relación de elementos, síntesis, concienciación de la intuición, abstracción, iniciativa, expresión gráfica y escritura.

La fase de la textura se concibe desde lo que su definición implica: la estructura y la disposición de las partes de un cuerpo, de una obra (Real Academia Española, s.f., definición 1), a lo que puede añadirse que también puede ser la estructura de una acción, dimensión, acontecimiento, sustancia, circunstancia, por supuesto de un texto. En la etapa de la concepción y materialización del proyecto arquitectónico, se construyen las ideas poéticas y espaciales que lo configuran ante la teoría, práctica, experiencia y contexto, estudiadas anteriormente. Se configuran las acciones que se desarrollan desde el entendimiento de la arquitectura como un hecho mediador, conjugado por los estadios anteriores y la idea de la enunciación. Textura también involucra la operación de tejer, es decir, la interacción entre experiencias, modos de operación, relaciones, materialización y presentación del proyecto.

La contextura la define el Diccionario de la Real Academia Española (2019) como la "disposición y unión respectiva de las partes que juntas componen un todo". En este estadio, se articulan las nociones conceptuales con la concreción arquitectónica. Se trata de llevar a cabo las ideas que desde la concepción poética se han generado. Para ello, se involucran los detalles tecnológicos y los sistemas infraestructurales que repercuten en impactos sociales y ambientales. 
En este estadio, se interrelacionan soluciones globales con aportes locales en cuanto a soluciones tecnológicas. Aquí el estudiante conjuga pensamiento poético con pensamiento técnico, convierte la propuesta en un hecho concreto, medible. Es el momento que evidencia lo conmensurable de un proyecto, que según Kahn (Ngo, 2002) proviene del mundo inconmensurable de las ideas. En la contextura, el participante se sumerge en un proceso, donde de manera individual o colectiva, se relaciona con el mundo de la producción de componentes arquitectónicos y todo lo que involucre sistemas constructivos, estructurales e instalaciones, desde una visión que aporte a los procesos globales y locales en la arquitectura. Este estadio no siempre está presente en el proceso de aprendizaje de la proyectación, ya que depende del requerimiento general de programa de Arquitectura para el semestre.

Son estas ocho expresiones las que, como estadios, configuran el dispositivo discursivo que produce un medio genérico para la proyectación de la arquitectura. Se activa así la gestación y producción de tantas posturas en arquitectura como proyectos haya en cada proceso. Los modos en que cada participante asume la proyección desde la enunciación evidencian que se han activado el pensamiento deductivo, crítico y creador.

Estos ocho estadios conjugan aprendizaje teórico y práctico materializado en un proyecto que ha sido la resultante de un transitar entre investigación, experimentación, conceptualización y concreción (Piñón, 1999), fusiona fronteras en las capacidades perceptivas (Gastón y Rovira, 2007) del estudiante y estimula, mediante el descubrir y despejar incógnitas, su vinculación con aquello que proyecta. Por otra parte, pone la crítica propositiva y creadora como protagonista del proyectar, ya que "la crítica evita que la teoría y la práctica se desarrollen por separado" (Martí, 1999, p. 62). Es así como, el dispositivo discursivo a través de la enunciación hace que en el participante confluya conocimiento y disfrute (Archilla Pérez, 2008), en pro de su evolución cognitiva. 


\section{Resultados. Las cuatro enunciaciones y su desarrollo como enseñanza del proyecto}

Las cuatro enunciaciones para materializarse se alejan de una concepción y concreción arquitectónica destinada a la resolución de programas y abocada a lo funcional sin vincularse con lo experiencial. También se alejan de una arquitectura que se queda en lo estandarizado y racional del ser humano, que no transita por sus experiencias y emociones (Machado, 2013). Sin embargo, se acercan a materializaciones que consideran la producción de la realidad a partir de sistemas discursivos (Pinardi, 2015) y la enseñanza del proyecto arquitectónico es enfocada desde la constitución de un ser contemporáneo (Agamben, 2011a). Es en este tránsito que surgen las formulaciones de las enunciaciones proyectuales como visiones ante situaciones urbanas y territoriales que afectan los modos de habitar. En consecuencia, la enseñanza de la proyección arquitectónica se despliega como un hipertexto, se gesta y desarrolla mediante la investigación crítica y una argumentación sustentada en la síntesis, abstracción y/o intuición de la enunciación propuesta a partir de un discurso textual y espacial coherente. $\mathrm{Al}$ tratarse la estructura del proceso arquitectónico como un hipertexto, los órdenes en la consecución de estos ocho estadios pueden alterarse, romperse, transgredirse y comenzar desde el último. Pero la conversión de estos procesos en conocimiento requiere de una expresión estructurada ordenada o no, que manifieste su procedencia de un modo tangible. Hasta ahora se ha seguido una prosecución lineal con posibilidades de apertura hacia otros órdenes. Ahora bien, llevar a cabo el desarrollo de las enunciaciones y estimular las posibilidades de pensamiento, crítica, creación y disfrute del aprendizaje en la arquitectura, busca que cada individualidad trabaje en colectivo, en una participación constante entre todos los participantes, mediante discernimientos y crítica.

Desde aquí nacen las enunciaciones que serán tratadas en este artículo: 
1. "El origen es ahora principio de impermanencia", en el cual el origen es el lugar fundacional de la ciudad de Maracaibo, la costa; el principio es un nuevo inicio, además de un nuevo modo arquitectónico, y la impermanencia es el carácter de la arquitectura que sobre la costa se infiltra o irrumpe con espacios habitables propuestos a partir de las experiencias que demanda el lugar.

2. "Naturalezas compatibles", como una construcción que sintetiza la búsqueda de la arquitectura en relación armónica con las dinámicas ecosistémicas. Una enunciación trabajada desde el área de protección natural del Relámpago del Catatumbo (Venezuela) y Cartagena de Indias. Esto es, se busca que se proyecte una arquitectura que dialogue con las cualidades de estos patrimonios de la humanidad.

3. "Sobre las sobras" busca construir espacios habitables en terrenos que en la ciudad de Maracaibo son utilizados como vertederos informales o dejados como espacios de la urbanidad que han quedado fuera de todo testimonio.

4. "La casa de Alicia en el país de las maravillas" es el lugar para la vida de una familia disfuncional, en la cual se estudia su experiencia espacial y el lugar donde esta habitará, se proyecta así una CASA del morador y no del autor.

\section{El origen es ahora principio de impermanencia, 2005}

Este proceso se llevó a cabo en el cuarto y sexto semestre del Programa de Arquitectura de la Universidad del Zulia, durante el primer periodo del año 2005. Participaron 20 estudiantes, los cuales inauguraron este método en la Facultad de Arquitectura de dicha Universidad. En este contexto, se propuso el dispositivo discursivo y se desarrolló de la siguiente manera:

Texto: el origen es ahora principio de impermanencia. 
Subtexto: se construyó mediante la elaboración de un texto individual, en el cual cada participante exponía un punto de vista del significado de la enunciación; entre ellos destacan: volver al origen en la forma de construir; sensibilidad hacia los ecosistemas naturales; trabajar históricamente el origen de la ciudad de Maracaibo; centrarse en la necesidad humana del habitar (Machado, 2009). Luego de esto, se acordó realizar una estrategia proyectual para la recuperación de la costa de la Ciudad de Maracaibo, para atravesarla mediante una arquitectura temporal que inicie la relación entre ambas. Este subtexto desde la enseñanza de la arquitectura busca entrenar la mirada que explora el velo de una realidad cotidiana de la ciudad, y explorar a través de lo textos de los participantes la perspectiva y profundidad con la cual aborda la enunciación.

Hipertexto: se realizaron dos sesiones, cada una de 3 horas, de intercambios de lecturas sobre reflexión y crítica de arquitectura contemporánea, de la mano de autores como Faderico Soriano (2004), Ignasi de Solá Morales (1998), Ricardo Devesa (1998), Terence Riley (1996) y Stan Allen (1997). Reflexiones sobre la ciudad y el territorio, a través de Ignasi de Solá Morales (2002). Reflexiones sobre la realidad contemporánea: Italo Calvino (1998), Deleuze y Guattari (2003). Conocimiento de la arquitectura local: Andrés García (1991), Graziano Gasparini y Luise Margolies (1986; 2005). El intercambio de las lecturas condujo a reforzar el discurso de cada participante, así como también insertarlo en el contexto contemporáneo de la disciplina y de esta realidad en otras latitudes.

Contexto: la ciudad de Maracaibo. Se realizó un recorrido y dos visitas. El recorrido se hizo por la ciudad de Maracaibo y las dos visitas fueron en los espacios vacantes encontrados en los 40 kilómetros de costa. Desde esa exploración se detectaron cuatro ecosistemas naturales y urbanos diferentes. De manera colectiva, los participantes realizaron una síntesis de la ciudad de Maracaibo y, a partir de ésta, otra síntesis conceptual de los 40 kilómetros costa, la cual fue dividida en cuatro ecosistemas, asignados por equipo 
de participantes, cada uno de los cuales realizó estudios perceptuales y planimétricos para extraer una síntesis y propuesta conceptual. Al tener la síntesis de los ecosistemas por separado, cada participante se apropió de un sitio y, desde una experiencia perceptiva con el sitio, elaboró una síntesis, entre ellas: etapas de nitidez, Masa filtrante entre lo natural y lo precario, encuentro de opuestos como tribuna (Machado, 2013). La dinámica de este estadio del dispositivo entrena a los participantes en superponer información planimétrica y vivencial para la toma de decisiones a partir de la articulación entre los tres estadios para abordar los siguientes.

Pretexto: Se realizó un experimento con 750 botellas de PET de 2 litros, con las cuales se construyó un espacio temporal para los estudiantes de arquitectura en forma de pliegue (Machado, 2013). A través de esta manipulación de un material de desecho, que busca un entrenamiento manual, se inserta con una pausa entre los estadios para madurar lo concebido.

Texto y subtexto: este estadio se enfoca en la conceptualización para la materialización del proyecto a partir de las síntesis generadas en los contextos. Desde una mirada poética, el participante debe redactar un texto de 500 palabras, y esquemas, bosquejos, abstracciones, que explicasen el significado de su concepto y la materialización. Así surgieron, entre 21 propuestas: Enroscamiento emergente por [re]fracción de Aura Berríos (Figura 1A); Baliza a través de etapas de nitidez de Andrea Castro (Figura 1B); Horizonte como sujeción de una des-com-posición de Ana Montiel (Figura 1C); Entramado de acontecimientos a través de bandas operativas de Francisco Mavárez (Figura 1D).

Textura: Las cuatro propuestas fueron materializadas como se muestra en la Figura 1. Estas materializaciones evidencian posturas singulares a partir de exploraciones que atraviesan el medio y la problemática para expresar la relación entre la arquitectura, situación y lugar. 


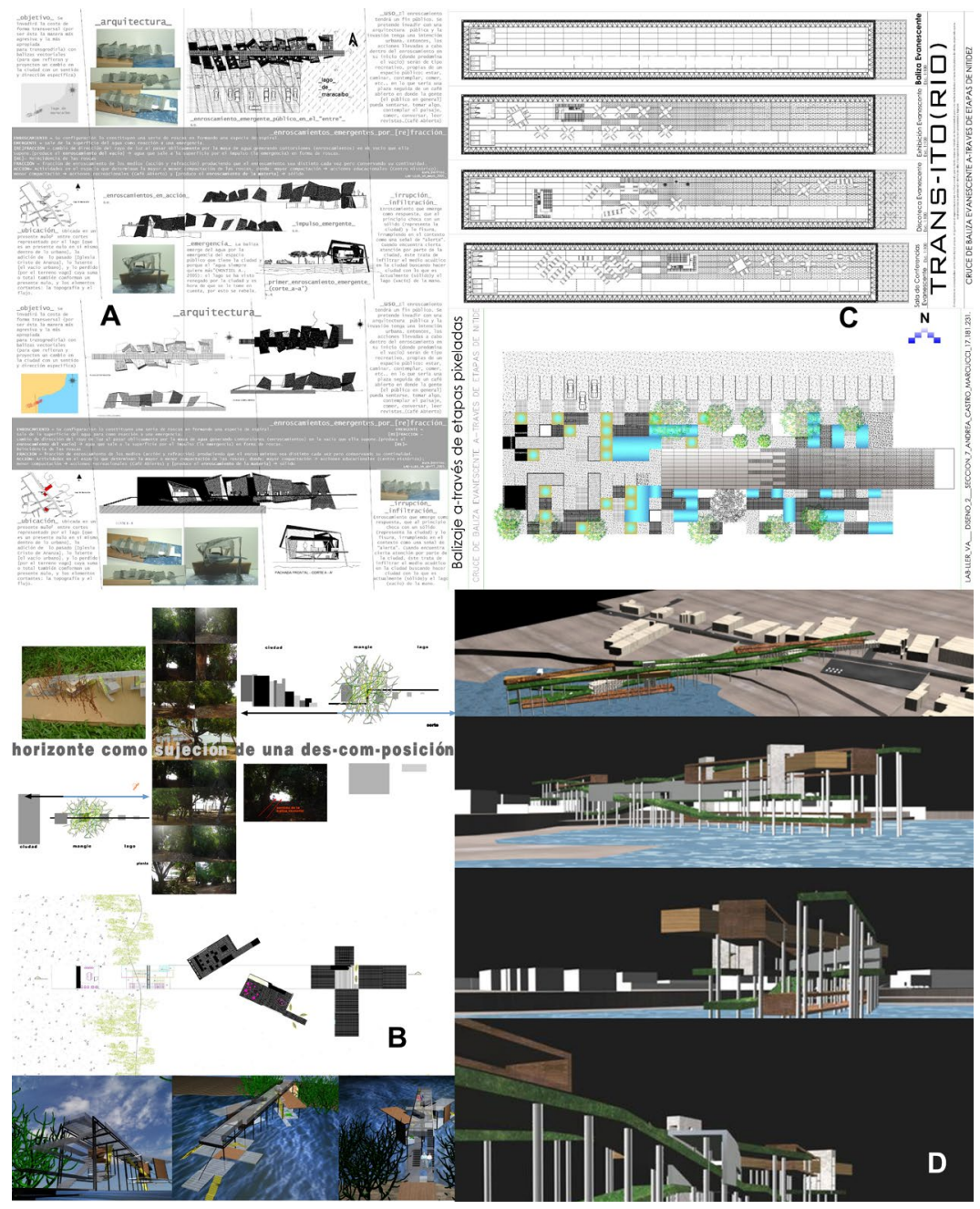

Figura 1. La textura de "El Origen es ahora principio de impermanencia". Fuente: Aura Berríos, Andrea Castro, Ana Montiel, Francisco Mavárez. 
Contextura: estadio que constituye la materialización al detalle en escala 1:20 (Figura 2) de una sección del proyecto. Etapa trabajada por cada participante en la que se evidencia de manera técnico constructiva cómo lo inconmensurable de las ideas puede ser construido en ese contexto.

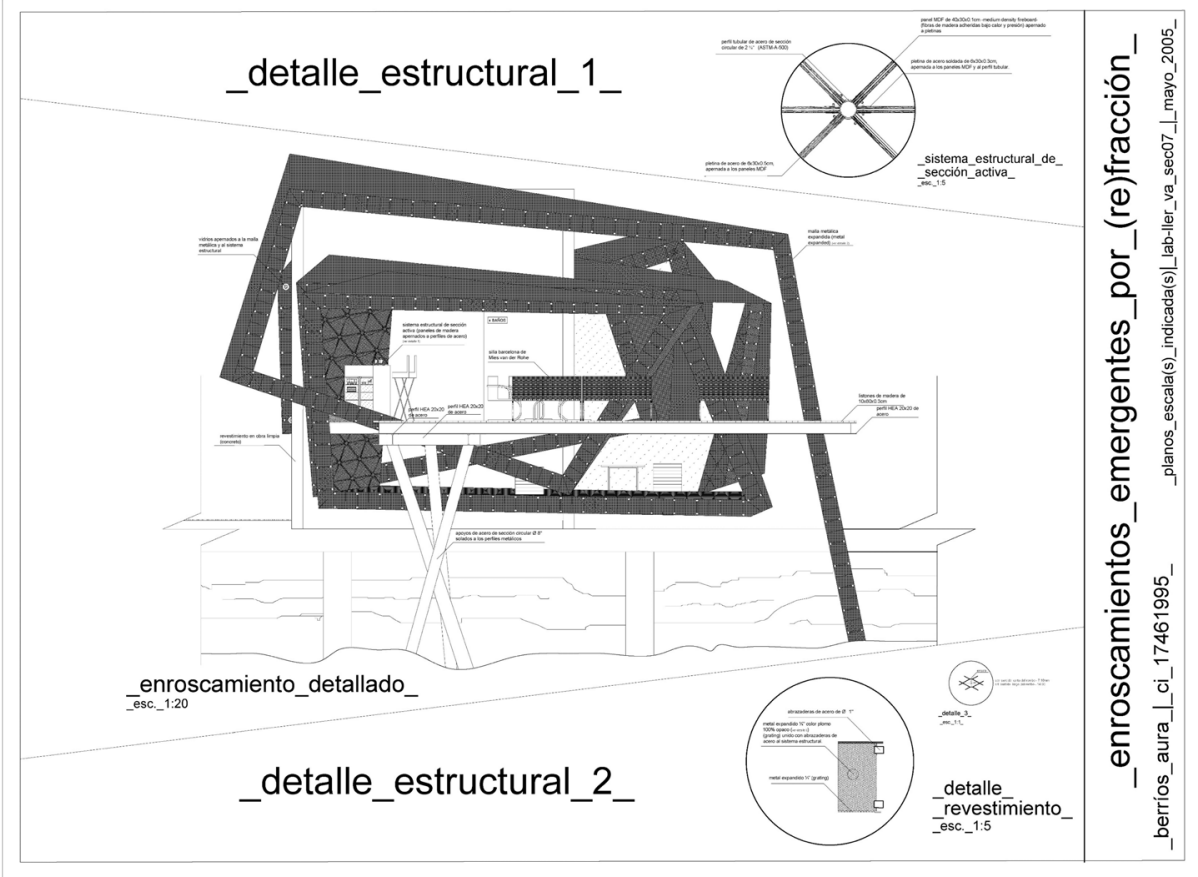

Figura 2. Contextura del Enroscamiento emergente por [re]fracción. 
En la enunciación "El origen es ahora principio de impermanencia", se conjugaron dos niveles del diseño arquitectónico (segundo y cuarto semestre), lo cual nutrió el aprendizaje con el intercambio creativo y de conocimientos entre ambos niveles. Una enunciación que abordó el pensamiento reflexivo, crítico y creativo en el tema la recuperación de la costa del lago de Maracaibo desde el presente en consideración con el pasado, cambió la mirada de este ser contemporáneo en constantes transformación, evidenció sus perspectivas sobre los posicionamientos territoriales de la arquitectura en el contexto en el que actúa. También incursionó en la historia desde una interpretación abordada con lenguaje arquitectónico contemporáneo. Esta enunciación también trabajó el valor del tiempo, temporalidad, impermanencia en la concepción de una arquitectura planteada como apertura en un lugar que necesita encontrarse con la ciudad. Mostró otro campo de acción para la experiencia y práctica del pensamiento crítico y reflexivo del participante. La puesta práctica del enunciado, a través del dispositivo discursivo, generó un proceso proyectual que nació de la reflexión, el discernimiento, las referencias y testimonios; preparó al participante para abordar propuestas en el paisaje desde iniciativas surgidas más que de imposiciones asignadas, y desplazó el protagonismo del programa hacia las formulaciones experienciales que el paisaje demande. Es así como mediante un modo de enseñanza del proyecto arquitectónico puede transformase el ser en un sujeto contemporáneo sensible a la proyectación de arquitecturas en apertura.

\section{Naturalezas Compatibles, 2008}

Fue la enunciación que inició el proceso de enseñanza proyectual en el noveno semestre del Programa de Arquitectura de la Universidad del Zulia durante el primer periodo del año 2008. Se realizó a través de un equipo conformado por 15 estudiantes y fue la séptima vez que se llevaba a cabo este proceso. 
Texto: Naturalezas compatibles.

Subtexto: esta etapa del dispositivo discursivo se realizó con los lugares a intervenir, seleccionados con la finalidad de conocer el sentido que los participantes le otorgaban a la enunciación. Con su realización, se evidenció que 12 de los 15 de participantes comprendió que la búsqueda de compatibilidad se refería a la relación entre ecosistemas sin intervención humana y arquitectura. Sin embargo, ningún participante se percató de la relación de compatibilidad entre la arquitectura contemporánea y la arquitectura patrimonial (Machado, 2009).

Hipertexto: Durante cuatro sesiones, de 1 hora cada una, se intercambiaron los contenidos entre lecturas que abordan los siguientes temas: Naturaleza y artificio: José Ballesteros (2008), Félix Guattari (2000), Luis Martínez Santa-María (2004), Iñaki Ábalos (2005), Ken Yeang (2001), Marta Feher (1998). Paisaje, ecosistema, lugar y arquitectura: Richard Rogers (2000), Iñaki Abalos (2005), Luca Galofaro (2004) Martín Heidegger (1951) Andreas Ruby (2006). El paisaje contemporáneo e histórico: Ignasi de Solá Morales (2003), Iñaki Ábalos (2005). De esta manera, se exploró desde los textos en diversas visiones sobre la relación entre la arquitectura, el paisaje y ecosistemas.

Contexto: la desembocadura del Río Concha en la Ciénaga de Juan Manuel, donde se produce el fenómeno del Relámpago del Catatumbo y el centro Histórico de Cartagena de Indias. Antes del reconocimiento del lugar, el equipo se dividió en dos, uno grupo migró a Cartagena y otros viajaron para la Ciénaga. Se visitaron ambos sitios mediante un proceso de inmersión día y noche, se tuvo contacto con las comunidades y se extrajo la información necesaria para determinar qué era lo conveniente como arquitectura para cada uno de los lugares. En clase, se realizaron los estudios planimétricos conjugados con el conocimiento de la experimentación para elaborar la síntesis 
que los llevaba a la conceptualización (Machado, 2009). En relación con la enunciación anterior, el contexto fue habitado en dos jornadas completas, pudiendo observar y sumergirse en las dinámicas durante el día y la noche. Se trasciende así la condición de observador a morador temporal del lugar, con lo cual se enriquece la percepción para abordar el lugar a proyectar.

Pretexto: en este estadio se trabajó a partir de una invitación recibida por parte de la "Bienal de Arquitectura de Maracaibo" para hacer la museografía durante una semana. Un ejercicio que puede ser visto como el opuesto de lo que propone la enunciación, ya que aquí se trabaja el interior de un espacio ambientalmente controlado.

Texto y subtexto: tras salir de la pausa que implica el pretexto, los participantes abordaron la conceptualización mediante la experiencia y la síntesis obtenidas en la etapa del contexto. Para ello, se les solicitó un texto de 500 palabras, acompañado por esquemas, abstracciones, deducciones, interpretaciones, gifs, videos, donde explicaban la materialidad poética de la arquitectura en compatibilidad con el lugar. Entre las 15 propuestas surgieron los siguientes conceptos. Para la Ciénaga: vacío re_velado de Maricarmen Coello (Figura 3A); Injerto de naturalezas traspuestas de Daniela Hinestroza (Figura 3B). Para Cartagena: Entre tensiones de fuga de Carla Nones (Figura 4A); Brotes como des_borde de tiempos de María Meléndez (Figura 4B).

Textura: Las propuestas generadas evidencian pluralidad en las formas de hacer compatibles la arquitectura con el medio en el que se insertan, muestran cómo a través de múltiples estrategias, que van desde el contraste, mímesis, desaparición, emergencia e infiltración, la arquitectura puede entablar relaciones armónicas entre su expresión contemporánea y el medio o lugar (Ver Figura 3 y 4 ). 


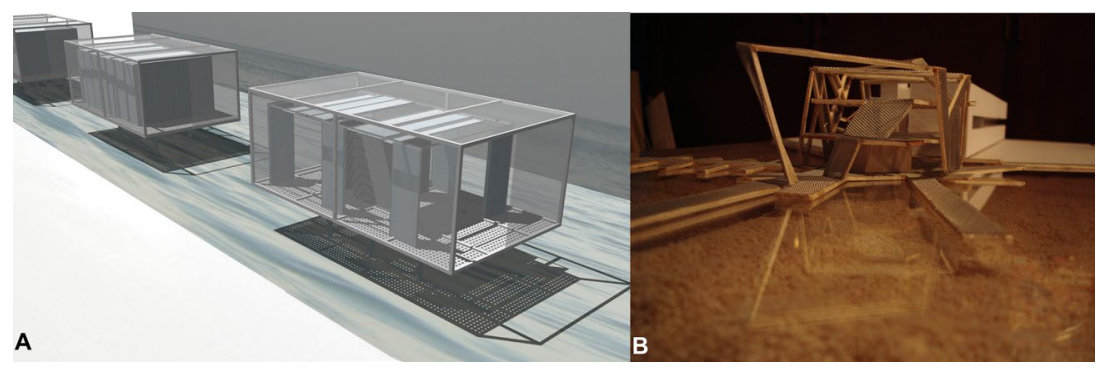

Figura 3. La textura de "Naturalezas compatibles" Ciénaga de Juan Manuel. Fuente: Maricarmen Coello, Daniela Hinestroza.
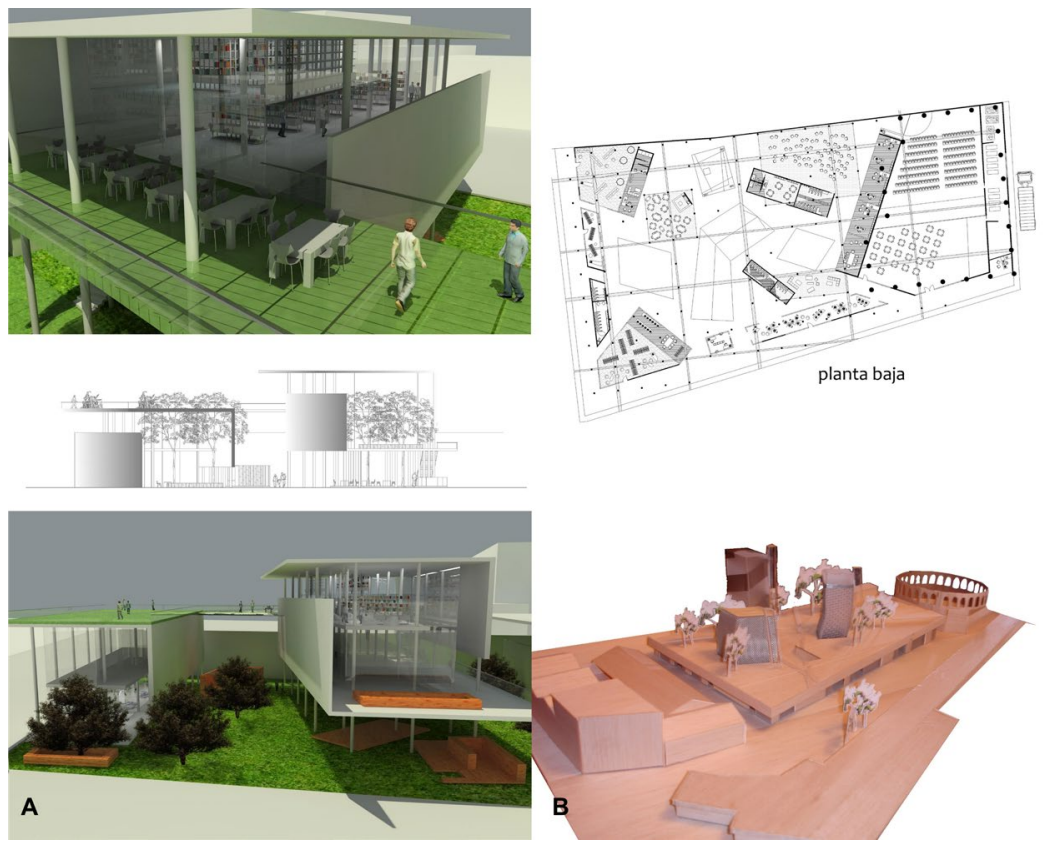

Figura 4. La textura de "Naturalezas compatibles" Cartagena de Indias. Fuente: Carla Nones, María Meléndez. 
La enunciación "Naturalezas compatibles" continúa con el abordaje del aprendizaje del proyecto arquitectónico que afianza el pensamiento crítico, reflexivo y creativo. Su proceso se condujo hacia la concienciación con los ecosistemas naturales y lugares históricos, ambos patrimonios de la humanidad. Ahondó en el trabajo desde una forma de cuidado que va más allá de la conservación, y puso en diálogo el medio con la arquitectura, sin interrumpir las dinámicas de ninguno de los sitios. Se entrenó al estudiante en una forma de pensamiento que hace énfasis en ir más allá de subsanar situaciones para abordarlas desde el fondo del problema. Propuso diversos modos de arquitectura que actúan desde la deferencia, como cuidado y noción de futuro de ambos patrimonios. La transformación que persigue esta enunciación en el participante vino dada por la exaltación de una conciencia que trabaje en el cuidado y explore los modos de sinergia en el abordaje de la arquitectura hacia el lugar.

\section{Sobre las sobras, 2009}

Esta enunciación se formuló para estudiantes del quinto semestre del Programa de Arquitectura de la Universidad del Zulia, en el segundo periodo del año 2009. Un curso conformado por 23 estudiantes. Se retomó la experiencia de la primera enunciación formulada a partir de una generalización sin referencias.

Texto: Sobre las sobras.

Subtexto: este estadio se abordó desde la escritura del texto, complementado con la realización de un cadáver exquisito que conectara las pistas de sus textos para definir el tema abordar. Dos métodos sin un resultado concreto, por lo cual se procedió a formular las siguientes preguntas: 1) En una ciudad ¿Cuáles espacios son los sobrantes? De allí surgieron respuestas que nombraban vertederos, cauces agua, terrenos abandonados, terrenos sin ocupación 
previa, etc. 2) ¿Cuáles experiencias son las propicias para desarrollar en esos lugares? De esta manera, se obtuvieron respuestas heterogéneas en cuanto a experiencias de morada, disfrute, estudios, cultura, etc., ya que, como es evidente, dependían más de la ubicación que de una utilidad en sí. Fue de esta manera como se concluyó que la estrategia para ese semestre era abordar los espacios residuales de la ciudad de Maracaibo. En otro orden de ideas, la experimentación de este estadio demostró que para algunas enunciaciones deben utilizarse otro tipo de herramientas, que complementa la exploración de las situaciones que velan el enunciado.

Hipertexto: se realizaron 3 sesiones, de 1 hora cada una, para intercambiar los contenidos de los siguientes temas: Sobre lo que está al margen: Michel Foucault (1977); Sobre otros paisajes: Jimena Martignoni. (2008), Kevin Lynch. (2005), Rem Koolhaas. (1997), Josepa Bru y Conxita Balcells (2002), Iñaki Ábalos y Juan Herreros (1997), Ignasi De Solá Morales (2002), Francesc Muñoz (2003), Josep María Montaner (2008), Florian Belgel y Philip Christou (1999), Javier Maderuelo (2003). Arquitectura contemporánea: Faderico Soriano (2004), Ignasi de Solá Morales (1998), Stan Allen (1997), Ignacio Lewkowicz y Pablo Sztulwark (2002), Manuel Gausa (2005). De la misma manera que en las enunciaciones anteriores, se mezcla el texto con la percepción desde distintos puntos de vista para enriquecer y pone en juego el pensamiento crítico de los participantes.

Contexto: esta enunciación, como se dicho anteriormente, aborda espacios residuales en diferentes zonas de la ciudad de Maracaibo, entre ellos: una cancha de atletismo abandonada en la costa; un terreno atravesado por un cauce de agua utilizado como vertedero; un lugar vacante, nunca utilizado, poblado por abundante vegetación e invadido por desechos domésticos; y un terreno industrial abandonado. Los lugares fueron visitados, relevados y se realizaron en ellos prácticas experienciales como, por ejemplo, mirar al 
cielo. También recorrer el lugar con ayuda de otro compañero y cerrar los ojos, orientar el frente del cuerpo al lugar de donde provienen las brisas, tumbarse sobre el suelo, en definitiva, adquirir diferentes posturas y observarlo desde diferentes puntos de vista durante distintas horas del día. Luego debían exponer la experiencia y, desde allí, plasmarla en la planimetría para incorporarle la información planimétrica y otros requerimientos urbanos (Machado, 2009). Tomando como pauta la experiencia de la etapa contextual de la enunciación anterior, modificada ahora con visitas ocasionales en distintos períodos del día y la semana, se realizaron los diferentes reconocimientos de los lugares en los cuales se iba a revertir su condición. Esta recurrencia y forma de observación y exploración del sitio condujo a profundizar en la exploración del lugar.

Pretexto: en esta etapa se elaboró un ejercicio de relación entre obras de arquitectura que en apariencia no muestran ninguna relación, pero que en el fondo tienen un elemento coligante. Es así como se descubrieron las relaciones entre: 1) El edifico del Mundo Árabe proyectado por Jean Nouvel y el Blur Building de Diller \& Scofidio. 2) El monumento homenaje a las víctimas del Holocausto Peter Eisenman con el Monumento a la Zulianidad. 3) Parque la Villete de Bernard Tschumi y la ampliación del Museo Judío en Berlín de Daniel Libeskind. 4) Biblioteca Phillips Exeter de Louis Kahn y espacio para la meditación en la sede de la UNESCO de Tadao Ando. 5) Fundación Cartier de Jean Nouvel y Blanco sobre blanco de Kasimir Malevich. Este ejercicio contribuye a estimular el pensamiento inductivo del participante, a partir del cual es entrenado para entablar relaciones inesperadas. 
Texto y subtexto: en esta etapa se generó la conceptualización a partir de los estadios anteriores, que por primera vez se le suma la etapa del pretexto. De igual manera que en los casos anteriores se realizaron los textos y los esquemas con las mismas características. Se generaron así 23 conceptos, entre los cuales destacan: Aerotorios de Manuel Beltrán (Figura 5A); Vallas habitadas; Virginia Dávila (Figura 5B).

Textura: las propuestas generadas en esta etapa evidencian exploraciones especulativas en referencia a la naturaleza de lugar, las cuales han sido tomadas como punto de partida para formular diversos modos de habitar. Por ejemplo, los "Aerotorios" exploran la posibilidad de habitar en el aire y las vallas habitadas, se valen de las formas de las vallas de atletismo para posicionarse sobre el territorio (Ver Figura 5).
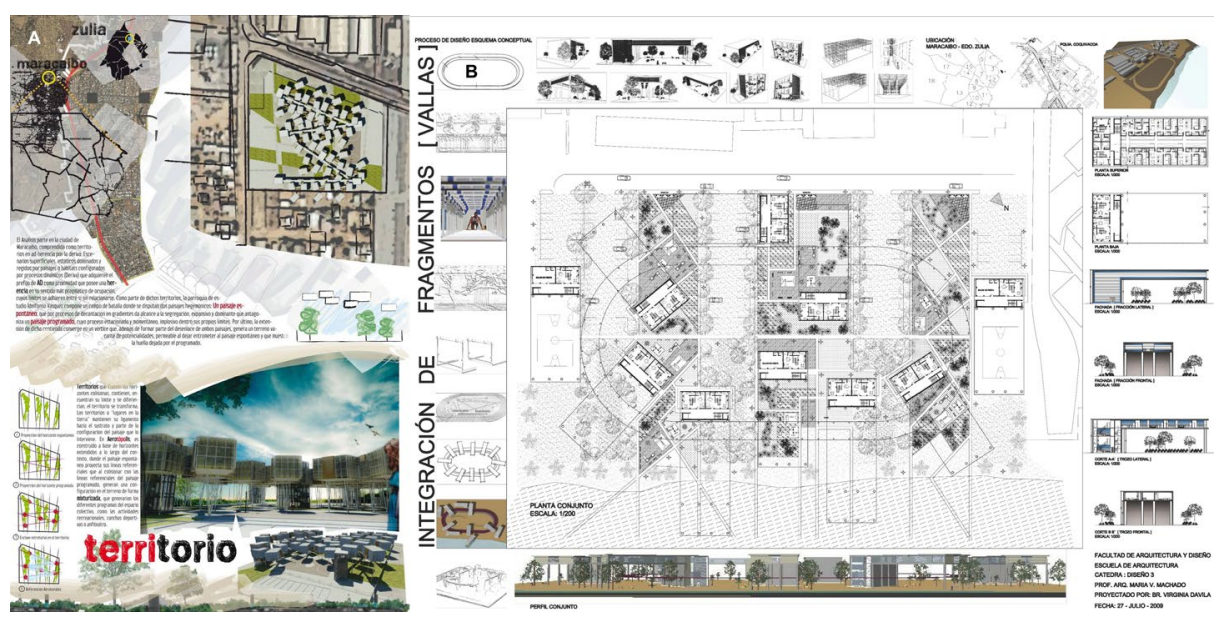
Con esta enunciación, se incorporan el deterioro, las lógicas informales, el caos, las carencias, el abandono, el des-orden al aprendizaje de la arquitectura que, más allá de mostrar sensibilidad, busca introducirse y actuar dentro de esas dinámicas. Pasar de idear "paisajes bajo el cielo" (Gausa, 1998) a construir relaciones desde lo marginado. Transformó la percepción del participante sobre estos temas; los entrenó en la formulación y despeje de inferencias y en indagar las posibilidades de los inesperado. La trascendencia de esta enunciación, como parte de la enseñanza del proyecto arquitectónico, lo constituye la idea de sacar a la luz lo que está allí que antes no había sido visto, como lo hiciera Marcel Duchamp con "La fuente" (1917). Es decir, conlleva a mirar desde otras perspectivas, a buscar tras lo evidente de las cosas y estimular directa y exponencialmente el pensamiento creativo.

\section{La casa de Alicia en el país de las maravillas, 2011-2018}

Esta enunciación se desarrolló por más de 7 años con estudiantes del cuarto semestre del Programa de Arquitectura de la Universidad del Zulia. Cursos que oscilaron entre 15 y 25 estudiantes. La primera vez que se formuló como enunciado fue el primer momento en que se mencionó el qué acompañado de una metáfora.

Texto: La casa de Alicia en el país de las maravillas.

Subtexto: como en los anteriores casos, se realizó el texto a partir del enunciado y en conocimiento del "qué". Correspondía entonces despejar la metáfora enunciada y explicar por qué ese "qué" enunciaba una casa y no un hogar, espacio doméstico, vivienda, domicilio, morada, habitación, residencia, villa, refugio. Del amplio espectro de estudiantes que ha elaborado este ejercicio, la mayoría hace referencia a la obra de Carroll; otros explican que Alicia son ellos; otros hablan del lugar de la casa como un lugar utópico; 
otros entran a expresar cuestiones psicológicas a las que remite la obra; otros que Alicia es feminidad, entre otras. Esta enunciación es presentada con un trasfondo metafórico preciso y definido: la casa para el ser latinoamericano en su contexto. Es casa porque la casa la construye la singularidad de quien la habita, es Alicia, no la de la novela, sino la de película dirigida por Tim Burton, porque ella reconoce su lugar de enunciación gracias al viaje por el país de las maravillas, y el país de las maravillas como ironía de la sociedad latinoamericana contemporánea, para mostrarle al estudiante las oportunidades que subyacen en estas sociedades. También con esta enunciación, se saca a la vivienda del contexto tipológico, por eso se le atribuye ser casa y desde allí se invita a proyectarla, desde la comprensión de la experiencia espacial de quién habitará la casa. Un subtexto que, develado, convoca al participante a realizar su texto exponiendo la percepción de esa singularidad de la casa, lo que lo entrena en agudizar la mirada hacia una temática específica.

Hipertexto: este estadio es más breve que en el resto, ya que la investigación se enfoca en el significado de la enunciación y su correspondencia en la arquitectura contemporánea. Se realizaron 2 sesiones, de 1 hora cada una, para intercambiar los contenidos de los siguientes temas: Arquitectura contemporánea: Federico Soriano (2004), Ignasi de Solá Morales (1998), Stan Allen (1997). Sobre el habitar: Martin Heidegger (1951), Iñaki Ábalos (2008), Josep Quetglas (1997), Rafael Iglesias (2011). De esta manera, se exploró en conjugar sus posturas en relación con las visiones de los autores sobre el espacio doméstico para activar el pensamiento crítico a partir de la idea de otros reconocidos. 
Contexto: este estadio, en sus reiteradas realizaciones, aborda el territorio urbano desde diversas perspectivas, entre las cuales destacan: 1) Sitios de vivienda social que se hayan visto modificadas por los que allí habitan. 2) Sitios en el borde costero. 3) Terrenos donde habitaban las familias para las cuales se proyectó. 4) Zonas residenciales tradicionales en ruinas. 5) Lugares precarios.

El estudio de los lugares se elaboró como en las enunciaciones anteriores y se incluyó la dimensión de la familia disfuncional, con la que el participante entraba en contacto y observaba durante una jornada su comportamiento espacial, a través de lo cual se presentaron esquemas que sintetizaron las características espaciales de la familia.

Pretexto: este estadio se abordó con dos ejercicios distintos a través de los diferentes períodos de su implementación: uno fue la improvisación de una arquitectura instantánea elaborada en una hora con cuarenta y cinco minutos, cuya finalidad fue explorar en la conformación y procesos de las construcciones informales que se generan producto de las invasiones. El otro ejercicio propuso concebir un espacio mínimo en el cual se pudieran adoptar las distintas posiciones humanas, un ejercicio que hace conciencia de la encarnación de un cuerpo que habita.

Textura: esta enunciación ha sido la que ha derivado más expresiones de modos de habitar la casa. Entre la pluralidad han destacado: La casa como horizonte Elizabeth Lomelli (Figura 6A); la casa repartida. Valeria González (Figura 6B); Habitar el haz Stefanía Hernández (Figura 6C); La casa como contorno emancipado. Paula Cabral (Figura 6D). 
La casa de Alicia en el país de las maravillas evidencia una triada que conjuga: a) el modo de habitar de una familia y su percepción espacial; b) la diferencia entre la propia experiencia de habitar del participante con la experiencia del otro para quien se proyecta, alejándolo de modelar en base a su modo de habitar los espacios que son para el otro; c) el estudio del lugar iniciado en la experiencia del espacio y su contexto, mediado por un estudio morfológico y su relación con el contexto natural y cultural. Las casas de Alicia, aquí surgidas, devinieron como espacios en apertura hacia situaciones premeditadas e inesperadas de lo que implica la cotidianidad del habitar en ciudades latinoamericanas, inscritas en la franja intertropical. La vinculación de los participantes del segundo año de la carrera, con los distintos núcleos familiares y su contexto, condujo a su sensibilización con los problemas del entorno inmediato y los preparó para las formulaciones más comunes en su futuro profesional. Proponer esta enunciación que aborda, desde la intimidad, la diferencia en la forma de habitar de cada ser ha abierto el entendimiento de la arquitectura al servicio del otro, esto es, a concebirla como un acto de deferencia entre el ser humano y su medio. Cada una de las propuestas se sale de la idea estandarizada de vivienda y las comprende desde "las formas de la alteridad propias de la realidad latinoamericana" (Machado et al., 2014, p. 95). 


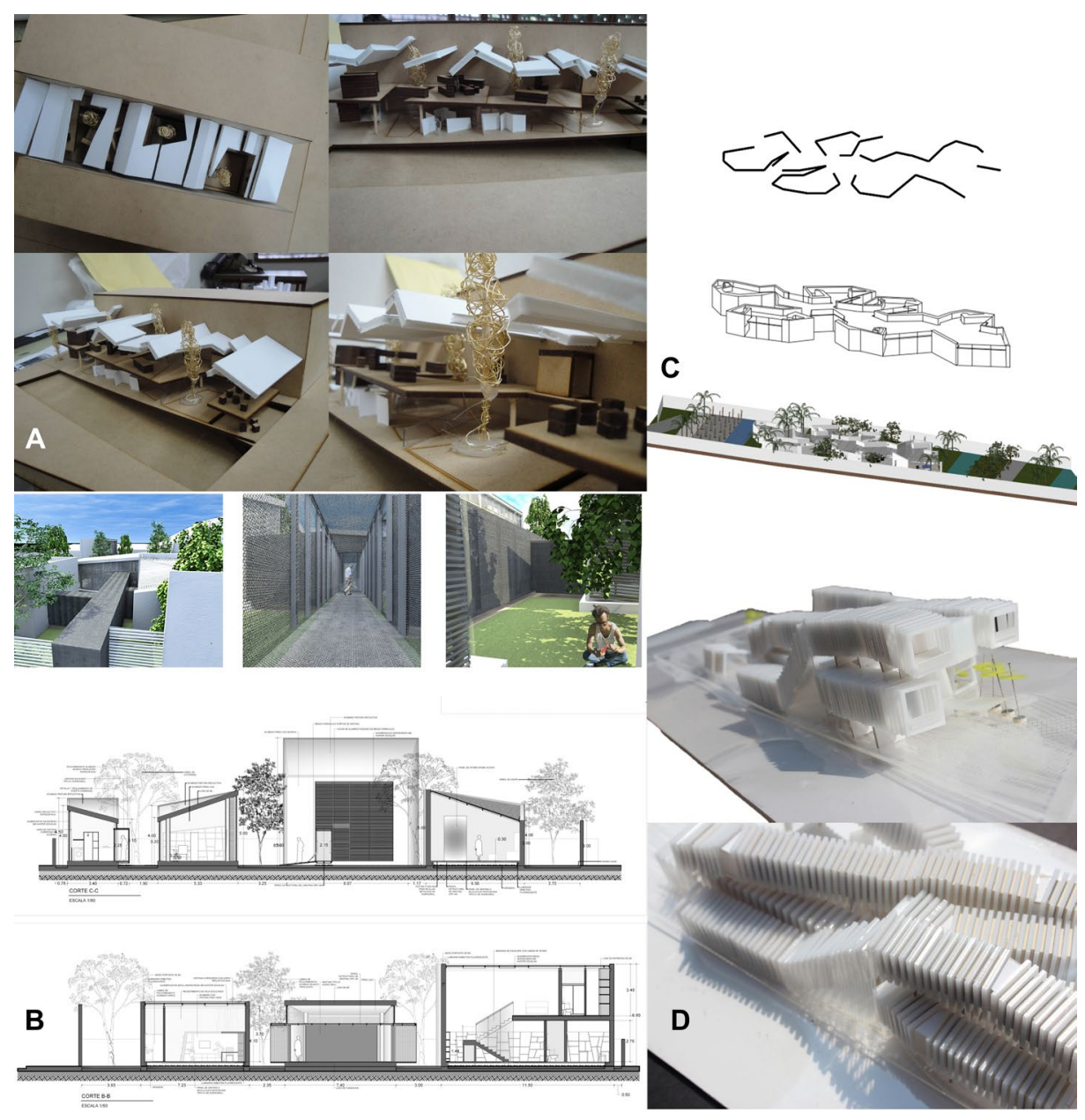

Figura 6. La textura de "La casa de Alicia en el país de las maravillas". Fuente: Elizabeth Lomelli, Valeria González, Stefanía Hernández, Paula Cabral. 
El aporte de las enunciaciones en el aprendizaje del proyecto arquitectónico, lo constituye la formulación de la enunciación, alejada explícitamente del contenido programático y el dispositivo discursivo producido para ello. Dispositivo que ha sido comprobado y adaptado ejercicio tras ejercicio, como se mostró a través de las cuatro enunciaciones anteriores. Dispositivo que obtiene de la palabra y concepto de "texto" su modo de proceder. Dispositivo que genera un proceso de aprendizaje a partir del hacer y descubrir la enunciación para interiorizar los conocimientos. Dispositivo que media, a través de una postura crítica, la posibilidad de producir espacios distintos a los generados a través de la proyección que responde al tema programático.

\section{Conclusión. El aporte de la enunciación en el aprendizaje de la arquitectura}

La enunciación para la construcción de un discurso proyectual conduce a una producción arquitectónica estrechamente vinculada con la investigación, reflexión y crítica. Por otra parte, faculta a los participantes a hacerse conscientes de su tiempo y de su lugar en la realidad. Les otorga a estos la posibilidad de desarrollarse ante la formulación del proyecto con una posición crítica y creativa sobre la realidad. Esta manera de desarrollar la propuesta arquitectónica no permite la preconcepción, se adentra en una realidad que y desde ella formula. Da pie para que la propuesta espacial provenga de una comprensión de lo que el ser y el lugar demandan y no se asuma como producto de un imperativo que se ha dispuesto de acuerdo con una normativa formulada desde el distanciamiento y desconocimiento del lugar específico.

El proceso, entonces, se desarrolla desde un dispositivo discursivo, basado en el concepto de texto y sus sufijos, para conformar gestores de otros órdenes, cuyos constituyentes (texto, sub-texto, hiper-texto, con-texto, pre-texto, sub-texto, textura y contextura) son esenciales en el desarrollo de un proyecto 
como discurso, inserto en una realidad colmada de significaciones. Un proceso que aporta en la trasformación del proponente, la concreción arquitectónica y el lugar donde se sitúa, ya que cada fase o estadio indaga desde un pensamiento crítico otras posibilidades de la arquitectura.

Es entonces que este dispositivo incide en el aprendizaje desde: el texto mediante su búsqueda por destacar cada uno de los valores de una posición y la diferencia de la percepción y reflexión sobre un discurso enunciativo. El sub-texto presta atención a lo velado de las apariencias, a la singularidad de las perspectivas y al ejercicio de la reflexión y crítica. El hiper-texto, a través de lecturas y testimonios en el arte, la arquitectura y la filosofía, indaga en el pensamiento analítico, interpretativo y especulativo. El con-texto lo hace a través del análisis y la síntesis, contempla el pensamiento deductivo, la experiencia perceptual, la práctica en la lectura planimétrica y el manejo multiescalar de la arquitectura. El pre-texto irrumpe para ampliar el imaginario y la experiencia hacia otras formas, incursiona en el pensamiento y prácticas especulativos, destaca y amplía las ideas conceptuales generadas en la textura. La textura que comienza en una concepción poética, construye un discurso y propuesta arquitectónica, ejercita el pensamiento creativo en lo discursivo, visual y espacial y la práctica proyectual que va de lo poético a lo material. La contextura es donde se aprende como la materialidad, los sistemas constructivos y toda la infraestructura se conciben para reforzar la poética conceptual que se genera en la textura.

Enunciación y dispositivo discursivo se han conjugado para construir una forma de aprender arquitectura que observa, indaga, experimenta y practica su producción mediante la trascendencia del oficio, ya que actúa de manera transversal en el lugar donde se inscribe, media con el contexto en tiempo y espacio y hurga desde sus inherencias para mediar entre el ser y el medio. 
Las enunciaciones por las que se ha transitado en la aplicación de este modo de aprendizaje de la arquitectura, han contribuido a la transformación del sujeto en un ser contemporáneo que inicia su proceso desde un sentido teórico en un contexto latinoamericano. Enunciaciones como prácticas inversas a lo que afirma Joan Campàs Montaner: "La civilización europea es una civilización del conocimiento (del logos, de la palabra). Hace depender el actuar del conocer (cogito ergo sum). La civilización americana es una civilización pragmática, de la acción ("existo porque hago")" (2010, p. 56). Enunciaciones que infieren la necesidad, en este tipo de contextos, de activar la conciencia de reflexión que deviene de la práctica y la experiencia para convertirlo en conocimiento. Un proceso que precisamente surge de la palabra, no solo como sintagma, sino como concepto, es decir, como parte de un discurso y experiencia. Un discurso textual que es transformado en otro lenguaje, el arquitectónico. Se genera de esta manera un intercambio entre el conocimiento y la acción, que parte de la experiencia latinoamericana.

Es así como un dispositivo, originado desde el entendimiento de ser contemporáneo: 1) Aborda un aprendizaje basado en la investigación, crítica, reflexión, experiencia, y experimentación, nutrido también de acciones "imprevistas". 2) Busca desplazar las preconcepciones de la modernidad para conformar posturas, puntos de vistas, acciones y propuestas que consideran un gran número de dimensiones de la realidad, cuya finalidad es conciliar el ser, el lugar y los ecosistemas planetarios. 3) Busca alterar las condiciones tendenciales, habituales y tradicionales de la arquitectura en ciudades latinoamericanas, que en la gran mayoría de los casos se mantienen ajena a la realidad que vive en cuanto al contexto que la posibilita. 


\section{Referencias}

Ábalos, I. (2005). Atlas pintoresco. Vol. 1: el observatorio. Barcelona, España: Editorial Gustavo Gili.

Agamben, G. (2011a). Desnudez. Buenos Aires, Argentina: Editorial Adriana Hidalgo.

Agamben, G. (2011b). ¿Qué es un dispositivo? Revista Sociológica, 26(73), 249-264. http://www.scielo.org.mx/pdf/soc/v26n73/v26n73a10.pdf

Allen, S. (1997). From object to field. Architectural Design, 67(5/6), 24-31.

Archilla Pérez, D. (2008). Metodología del disfrute: Cinco habilidades a desarrollar en el proceso (Tesis Doctoral). Departamento de Proyectos Arquitectónicos Escuela Técnica Superior de Arquitectura. Universidad Politécnica de Madrid. España.

Arendt, H. (2009). La condición humana. Barcelona, España: Editorial Paidós.

Austin, J. L. (1955). Cómo hacer cosas con palabras (Edición electrónica). www.philosophia.cl / Escuela de Filosofía Universidad ARCIS. http://revistaliterariakatharsis.org/Como_hacer_cosas_con_palabras.pdf

Brisotto, C., Cassandra Murphy, C. y Battaglin Ramos, M. (2019). FREESPACE and the Citizen: Stories of Generosity from the Venice Architecture Biennale 2018. The Plan Journal, 4(1), 1-16. http://www.theplanjournal. com/article/freespace-and-citizen-stories-generosity-venice-architecturebiennale-2018 
Campàs Montaner, J. (2010). Los legados del arte del siglo XX. Materiales del curso: ARTE DEL SIGLO XX. Universitat Oberta de Catalunya. Barcelona. España. http://openaccess.uoc.edu/webapps/o2/bitstream/10609/79725/4/ Arte\%20del\%20siglo\%20XX_M\%C3\%B3dulo\%201_Los\%20legados\%20 del\%20arte\%20del\%20siglo\%20XX.pdf

Cordero, N. L. (2005). Siendo, se es. La tesis de Parménides. Buenos Aires, Argentina: Editorial Biblos.

Corominas, J. (1985). Etimología de Proyecto. Diccionario crítico etimológico Castellano e hispano. Tomo Me-Re. Madrid. España. Editorial Gredos.

Deleuze, G. (2009). ¿Qué es un dispositivo? En AA. VV., Michel Foucault Filósofo (pp. 155-163). Madrid, España: Editorial Gedisa.

Foucault, M. (1977). Dit et Écrits. Paris, France: Éditions Gallimard.

Fujimoto, S. (2010). El futuro primitivo. Revista El Croquis, (151), 198-213.

García-Hípola, M. (2014). Edificios con escala de paisaje. Agadir de Oma y Yokohama de Foa. ACE: Architecture, City and Environment = Arquitectura, Ciudad y Entorno, 9(26), 53-68. https://dx.doi.org/10.5821/ace.9.26.3562

Gastón, C. y Rovira, T. (2007). El proyecto moderno. Pautas de Investigación. Barcelona, España: Ediciones UPC.

Gausa, M. (1998). Arquitectura reactiva: marco Proneista = new reactive architecture: proneist frame. Revista Quaderns $=$ new reactive architecture : proneist frame, (219), 6-11. https://www.raco.cat/index.php/ QuadernsArquitecturaUrbanisme/article/view/240836 
Gausa, M. (2001). Arquitectrua es (ahora) geografía. (Otras "naturalezas" urbanas). Revista Arquitectura, (325). 14.01-14.21. https://www. coam.org/media/Default\%20Files/fundacion/biblioteca/revistaarquitectura-100/2000-2008/docs/revista-articulos/revista-arquitectura2001-n325-pag72-81.pdf

Gausa, M. (2005). Optimismo Operativo. Hacia un nuevo idealismo pragmático en Europa. Barcelona, España: Editorial ACTAR.

Holl, S. (2011). Cuestiones de percepción. Fenomenología de la arquitectura. Barcelona, España: Editorial Gustavo Gili.

Juaçaba, C. (2015). Humanidade 2012. ARQ (Santiago), (90), 80-85. https://dx.doi.org/10.4067/S0717-69962015000200017

Juarranz Serrano, A. (2017). Terceras Naturalezas en la génesis de arquitectura. La Fundación Francisco Giner de los Ríos (Amid.cero9, 2015). Revista Innovación e Investigación en Arquitectura y Territorio, 5(1). https://doi. org/10.14198/i2.2017.5.05

Koolhaas, R. (1997) S, M, L, XL. Nueva York, USA: Monacelli Press.

Machado, M. (2013). Desde la TRANSformación hacia la TRANSposición (Tesis Doctoral). Universidad del Zulia. Facultad de Arquitectura y Diseño. Maracaibo. Venezuela.

Machado, M. V., Noriega, A., Lomelli, E., Fung, S., Perozo, L., Servodía, M. A., González, V., Salas, E., Ormo, A., Sánchez, S., Toyo, A., González, V., Hernández, S., Cabral, P., Melean, M. V., González, S. (2014). La casa de Alicia en el país de las maravillas: la casa del SER en su contexto. I Congreso Internacional de Vivienda Colectiva Sostenible, Barcelona, 25, 26 y 27 de febrero de 2014. Máster Laboratorio de la Vivienda Sostenible del Siglo XXI, 2014, p. 90-95. 
Martí Aris, C. (1999). Silencios elocuentes (1ra. ed.). Barcelona, España: Edicions UPC.

Martínez Echeverri, L. y Martínez Echeverri, H. (1997). Diccionario de Filosofía ilustrado (1 ra ed.). Bogotá, Colombia: Editorial Panamericana.

Moneo, R. (2004). Inquietud teórica y estrategia proyectual en la obra de ocho arquitectos contemporáneos. Barcelona, España: Editorial Actar.

Montaner, J. (2008). Sistemas arquitectónicos contemporáneos. Barcelona, España: Editorial Gustavo Gili.

Montaner, J. (2014). Del diagrama a las experiencias, hacia una arquitectura de la acción. Barcelona, España: Editorial Gustavo Gili.

Ngo, D. (2002). Louis Kahn. Conversaciones con estudiantes (1 ra. ed.). Barcelona, España. Editorial Gustavo Gili.

Pinardi, S. (2015). Lo contemporáneo y sus definiciones (Conferencia). Exposición Panorámica. Arte Emergente en Venezuela. 2000-2012. Curaduría: Félix Suazo. Sala Trasnocho Arte Contacto, Caracas, Venezuela.

Piñón, H. (1999). Miradas intensivas. Barcelona, España: Edicions UPC.

Porras Collantes, E. (1981). Texto y subtexto de "Tlön, Uqbar, Orbis Tertius" de Jorge Luis Borges. Thesaurus: Boletín del instituto Caro y Cuervo, 36(3), 82-117.

Real Academia Española. (s.f.). Contexto. En Diccionario de la lengua española. Recuperado en 10 de febrero de 2019, de https://dle.rae.es/ contexto? $\mathrm{m}=$ form

Real Academia Española. (s.f.). Contextura. En Diccionario de la lengua española. Recuperado en 10 de febrero de 2019, de https://dle.rae.es/ contextura? $\mathrm{m}=$ form 
Real Academia Española. (s.f.). Pretexto. En Diccionario de la lengua española. Recuperado en 10 de febrero de 2019, de https://dle.rae.es/pretexto?m=form

Real Academia Española. (s.f.). Textura. En Diccionario de la lengua española. Recuperado en 10 de febrero de 2019, de https://dle.rae.es/textura?m=form

Ricoeur, P. (2001). Del texto a la acción. Ensayos de hermenéutica II. CDMX, México: Editorial Fondo de Cultura Económica.

Soriano, F. (2004). Sin tesis. Barcelona, España: Editorial Gustavo Gili.

Xubirí, X. (2004). Inteligencia Sentiente. Madrid, España: Editorial Tecnos.

Zabalbeascoa, A. (7 de septiembre de 2012). Muerte no, dimisión sí. Diario El País. https://elpais.com/elpais/2012/09/07/del_tirador_a_la_ ciudad/1347011900_134701.html

Cómo citar: Machado Penso, M. B. (2021). Sin programa. Aprendizaje proyectual en arquitectura a través de la enunciación. Revista KEPES, 18(23), 179-218. https://doi.org/10.17151/kepes.2021.18.23.7 